\title{
"A Proposed Single-Phase Five-Level PFC Rectifier for Smart Grid Applications: An Experimental Evaluation"
}

IEEE IECON Industrial Electronics Conference, Lisbon, Portugal, Oct. 2019.

This material is posted here with permission of the IEEE. Such permission of the IEEE does not in any way imply IEEE endorsement of any of Group of Energy and Power Electronics, University of Minho, products or services. Internal or personal use of this material is permitted. However, permission to reprint/republish this material for advertising or promotional purposes or for creating new collective works for resale or redistribution must be obtained from the IEEE by writing to pubs-permissions@ieee.org. By choosing to view this document, you agree to all provisions of the copyright laws protecting it. 


\section{A Proposed Single-Phase Five-Level PFC Rectifier for Smart Grid Applications: An Experimental Evaluation}

\author{
Vitor Monteiro \\ Centro ALGORITMI \\ University of Minho \\ Guimaraes, Portugal \\ vmonteiro@dei.uminho.pt \\ Jose A. Afonso \\ CMEMS-UMinho Center \\ University of Minho \\ Guimaraes, Portugal \\ jose.afonso@dei.uminho.pt
}

\author{
Nima Tashakor \\ Department of Electrical and Computer \\ Engineering - Division of MEAS \\ TU Kaiserslautern, Germany \\ tashakor@eit.uni-kl.de
}

\author{
Julio S. Martins \\ Centro ALGORITMI \\ University of Minho \\ Guimaraes, Portugal \\ jmartins@dei.uminho.pt
}

\author{
Mohamed Tanta \\ Centro ALGORITMI \\ University of Minho \\ Guimaraes, Portugal \\ mtanta@dei.uminho.pt \\ Joao L. Afonso \\ Centro ALGORITMI \\ University of Minho \\ Guimaraes, Portugal \\ jla@dei.uminho.pt
}

\begin{abstract}
The use of PFC rectifiers has assumed an increasingly preponderance, contributing in a decisive way to improve the power quality indices, since they allow to operate with sinusoidal current on the ac-side and with controlled voltage on the dc-side. In this paper is proposed a novel $\mathrm{PFC}$ rectifier that allows five-levels of voltage. As noted in the paper, it presents a number of interesting advantages when compared to the conventional five-level PFC rectifier, mainly because it requires less passive and active semiconductors to produce the different voltage levels and requires less hardware resources to implement the gate-driver circuits. The proposed five-level PFC (5L-PFC) rectifier operates in boost mode and has a single dc-link (although with a midpoint to achieve the various levels), being an important feature for applications in smart grids (e.g., smart electrical appliances and electric mobility chargers). The key topics of the 5L-PFC rectifier are addressed and discussed based on the analysis of the principle of operation. As current control strategy it was adopted the model predictive control. Experimental results in steady and transient state were considered for an effective validation of the 5L-PFC rectifier, verifying the operation with: sinusoidal current on the ac-side; multi-level operation with five-levels; controlled dc-link voltage.
\end{abstract}

Keywords - Five-Level, PFC Rectifier, Power Quality, Smart Grids, Model Predictive Control.

\section{INTRODUCTION}

The use of electricity has been steadily increasing over the last few decades, and power electronics converters have been tracking this progress to meet the various needs, whether for interfacing with the main grid or for interfacing with isolated grids. Some relevant studies about this concern can be found in $[1]^{\text {and in }}[2]$. Nowadays, beyond simply converting voltage and current levels, power electronics converters are increasingly responsible for ensuring operation with high efficiency and for meeting power quality requirements. Thus, the interest in power converters is increasing for different applications, which forces the emergence of new topologies, as well as power theories and current and voltage control techniques [3][4]. In this context, topologies of power factor correction (PFC) rectifiers are of particular interest, since employing these rectifiers it is possible to guarantee a sinusoidal input current and a controlled output voltage [5]. Several topologies can be identified in the literature, e.g., as the based on the boost, buck, or Cuk converters [6][7]. In particular, also framed with PFC rectifiers, multilevel converters reveal a line of converters with peculiar attributes to meet efficiency and power quality requirements [8][9]. In the early 1980s, the design of a multilevel converter structure, represented by the Neutral Point Clamped (NPC) topology, emerged [10]. Since then, new multilevel converter structures have emerged, with special emphasis on those that are based on flying-capacitor and cascaded full-bridge [11][12]. As its name implies, a multilevel converter differs from the other converters, since it can achieve a high number of voltage levels. In this way, the voltage produced by the converter is more similar to the fundamental component of the ac-side voltage, allowing to reduce the needs of the coupling filters. In addition, due to the particularity of several voltage levels, the voltage applied to each semiconductor is reduced contributing to improve the efficiency of the converter (e.g., switching and conduction losses are lower), reduce harmonic content of the controlled variables, and to obtain a faster dynamic response. Due to these characteristics, multilevel converters are assumed to be preponderant for a variety of applications, e.g., unidirectional active rectifiers, grid-tied inverters for on-grid systems, inverters for UPSs, and inverters for control of electrical machines [13]. In this perspective, a novel single-phase PFC rectifier with a multilevel characteristic is proposed in this paper, where the final application is related with electrical appliances in smart grids (e.g., electrical appliances at home level or EV battery chargers [14][15]). Since increasing the number of voltage levels imply an increasing of the requirements of hardware and software, a five-level PFC rectifier (5L-PFC) is an interesting solution to comply with a satisfactory correlation among voltage levels, passive filters, and power density. A 5L rectifier based on the well-known NPC is proposed in [16], where the final application is the interface of renewables. Similarly, in [17], [18] and in [19] are also presented $5 \mathrm{~L}$ rectifiers for interfacing renewables. A $5 \mathrm{~L}-\mathrm{PFC}$ rectifier with a structure based on the NPC is offered 


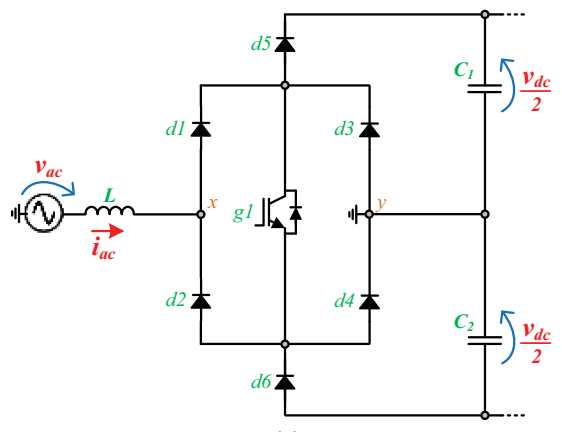

(a)

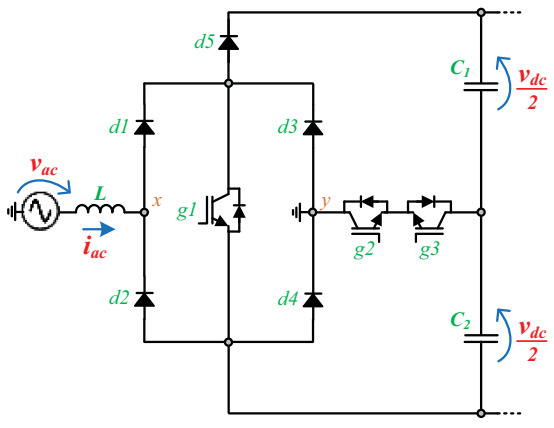

(b)

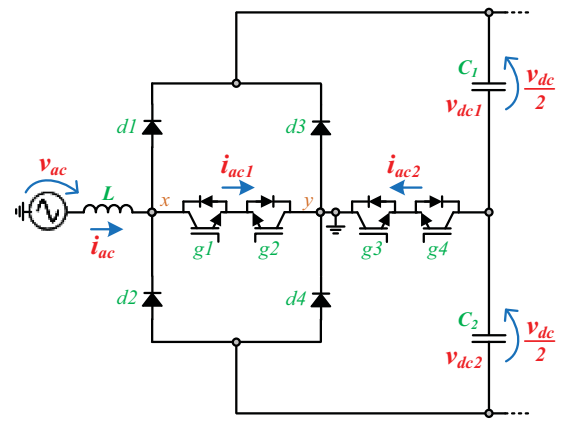

(c)

Fig. 1. Topologies of converters: (a) Two-level PFC VIENNA rectifier; (b) Three-level PFC VIENNA rectifier; (c) Proposed five-level PFC rectifier.

in [20] for three-phase applications, where the reduced number of components is a distinguished factor. In counterpart, in [21] is proposed a $5 \mathrm{~L}-\mathrm{PFC}$ rectifier for applications of motor drives. 5L-PFC rectifiers are proposed in [22], [23], and [24] (with some related aspects with this paper) for EV battery chargers. A bidirectional 5L converter is proposed in [25] as a shunt active filter. Generic 5L-PFC rectifiers that can be used for distinct applications, can also be found in the literature, as following presented: A VIENNA-type 5L-PFC rectifier is proposed in [26]; A bidirectional 5L buck rectifier is proposed in [27]; A T-type 5L-PFC rectifier is considered in [28]; Cascade symmetrical and asymmetrical 5L-PFC rectifiers are proposed in [29]; A buck-boost 5L rectifier is proposed in [30]; Cascading flying capacitor and an h-bridge is presented in [31]; A 5L packed U-cell is proposed in [32]. The proposed topology derives from the most common topology of PFC rectifier, which is composed of an ac-dc diode bridge followed by a dc-dc boost converter. This common PFC rectifier is classified as a two-level (2L) structure. Depending on where the inductor is placed (e.g., on the ac-side of the diode bridge), other arrangements of the same topology may be considered. From this conventional PFC rectifier, dividing the dc-link, it is obtained a topology identified as PFC VIENNA rectifier, which is shown in Fig. 1(a). In comparison to the conventional PFC rectifier, the VIENNA rectifier operates with a double-boost characteristic, allowing the operation with three-levels (3L) and requiring only one more diode (in comparison with the common $2 \mathrm{~L}$ PFC rectifier). In this sequence, using a bipolar and bidirectional cell, between the midpoint of the dc-link and the neutral wire, a five-level (5L) PFC VIENNA rectifier is obtained, as shown in Fig. 1(b). In comparison to the conventional PFC rectifier, this topology is not of the double-boost type, and requires only two more IGBT to produce the 5L. From the 5L-PFC VIENNA rectifier, it is possible to derive another $5 \mathrm{~L}-\mathrm{PFC}$ rectifier, which is proposed in this paper, as presented in Fig. 1(c). As shown, this 5L-PFC rectifier requires one less diode and one more IGBT, but allows to operate with reduced conduction and switching losses, since for producing any of the voltage levels less components are required. The main differentiating factors of this paper are: (i) The proposed topology aggregates the main advantages of the conventional 5L-PFC rectifiers; (ii) It has a reduced number of devices, does not present the double-boost characteristic, and it has only a split dc-link; (iii) The required switching devices are connected, two by two, with a common-emitter configuration, simplifying the gate-drive design (reducing the necessities concerning isolated power supplies); (iv) It is capable of operation even in case of failure of the switching devices (open circuit cases, but this is not validated in this paper); (v) Experimental validation of the 5L-PFC rectifier using a laboratorial prototype. An exhaustive comparison is out of the scope of this paper due to space restrictions. The rest of the article is organized according to: Section II presents the converter, extolling its main valences; Section III presents the control applied to the 5L-PFC based on a predictive strategy; Section IV presents the validation of the 5L-PFC, supported by computational and laboratory results with a developed prototype; Section V ends the paper with the conclusions.

\section{FIVE-LEVEL PFC RECTIFIER: PRINCIPLE OF OPERATION}

The 5L-PFC rectifier is shown in Fig. 1(c). In terms of hardware topology, the topology consists of four IGBTs $\left(g_{1}, g_{2}\right.$, $\left.g_{3}, g_{4}\right)$ and four diodes $\left(d_{1}, d_{2}, d_{3}, d_{4}\right)$. As it can be seen, the diodes $d_{1}, d_{2}, d_{3}$, and $d_{4}$ are used to form a conventional diode bridge. (similar to the conventional PFC rectifier). The sets of IGBTs $\left(g_{1}, g_{2}\right.$ and $\left.g_{3}, g_{4}\right)$ have two distinct functions: (i) The IGBTs $g_{1}$ and $g_{2}$ are used to obtain the voltage level 0 , respectively, in the positive and negative half-cycles; (ii) The IGBTs $g_{3}$ and $g_{4}$ are used to obtain the voltage levels $+v_{d c} / 2$ and $-v_{d d} / 2$, respectively, in the positive and negative half-cycles. Through this analysis, it is understandable to verify that it is only necessary to switch one IGBT at each time of the control period, when the objective is to obtain the voltage levels 0 , $+v_{d c} / 2$, and $-v_{d c} / 2$. Consequently, during a period of the grid voltage, the four IGBTs only change the state four times, i.e., once each IGBT (two in the positive half-cycle and the other two in the negative half-cycle). Both sets of IGBTs $\left(g_{1}, g_{2}\right.$ and $g_{3}, g_{4}$ ) assume a common-emitter configuration, however, a common-collector configuration could also be used, as well as another configuration to obtain a bipolar and bidirectional cell (e.g., a semi-controlled h-bridge structure). In both sets of IGBTs, the common-emitter configuration presents the main advantage of simplifying the gate-driver circuit. Since IGBTs are actuated with a gate-emitter voltage and require an isolated power supply, the common-emitter configuration requires only the use of one isolated power supply, since each set of IGBTs is referenced to the same potential (both emitters). It should be noted that other strategies can be adopted for the configuration of the IGBTs and their gate-driver circuits. As example, the IGBTs $g_{1}$ and $g_{2}$ may assume a common-emitter configuration and the IGBTs $g_{3}$ and $g_{4}$ are a common-collector configuration, or vice-versa. In both situations, two isolated power supplies are still required (in this situation an isolated power supply 


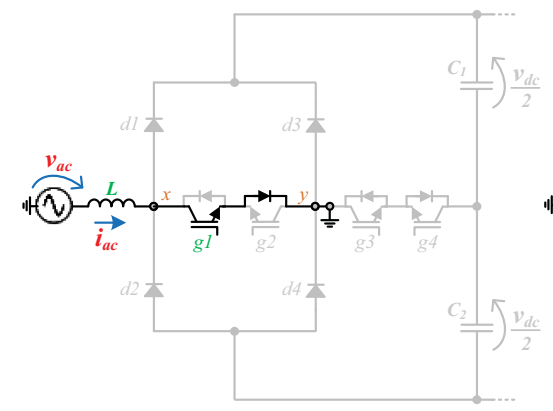

(a)

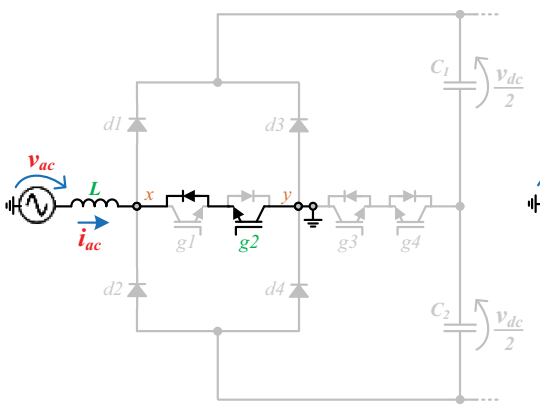

(d)

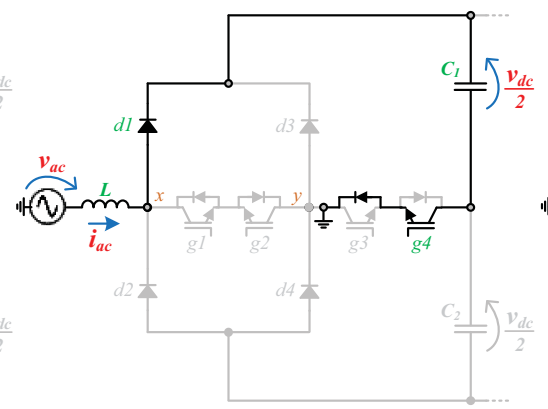

(b)

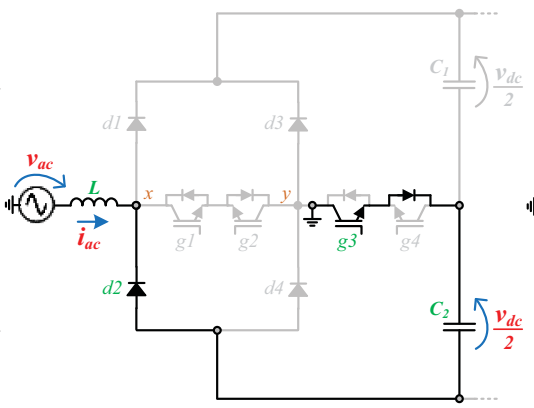

(e)

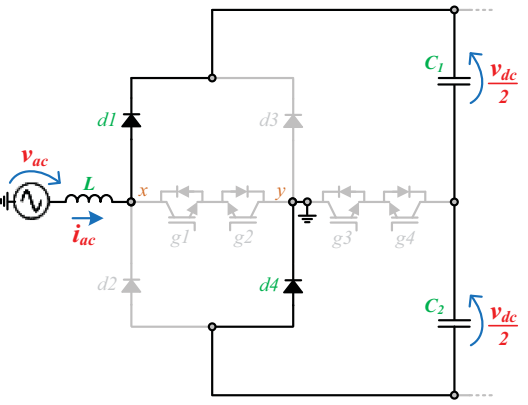

(c)

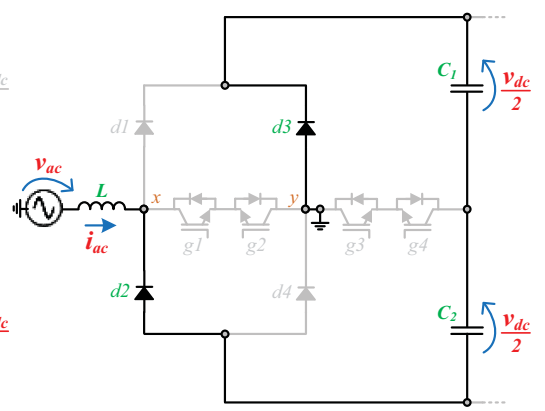

(f)

Fig. 2. Most convenient states that the proposed 5L-PFC rectifier can assume: (a)-(c) When $v_{a c}>0$; (d)-(f) When $v_{a c}<0$.

would be required for the IGBTs $g_{1}, g_{2}$, and $g_{3}$ and another for the IGBT $g_{4}$ ). As shown in Fig. 1(c), the proposed 5L-PFC rectifier consists of a diode bridge that interfaces between the ac-side and the dc-link, distinguishing the topology with a relevant characteristic, which is to allow the operation even in the eventuality of failures of the IGBTs (when they are always open) or the gate-drivers. Based on this rationale, the 5L-PFC rectifier allows up to five different situations (according to fault tolerance, when the IGBTs are in the off state, or when the gate-driver circuits stop working): (a) Situation in which no one of the IGBT fails and the topology operates normally with the five-levels; (b) Situation where all the IGBTs fails and the topology operates as a traditional diode bridge; (c) Situation where the IGBTs $g_{3}$ and $g_{4}$ fail and the topology can only operate with three-levels (level 0 being guaranteed by the IGBTs $g_{1}$ and $g_{2}$ ), by adjusting the control algorithm; (d) Situation where the IGBTs $g_{3}$ and $g_{4}$ fail and one of the IGBTs $g_{1}$ or $g_{2}$ also fails, where the topology operates as a diode bridge in one of the half-cycles and as active rectifier in the other half-cycle (with two-levels); (e) Situation where the IGBTs $g_{I}$ and $g_{2}$ fail and the topology operates only with the levels $+v_{d c} / 2,+v_{d c},-v_{d c} / 2$, and $-v_{d c}$ (thus, the level 0 cannot be guaranteed). On the other hand, when there are error situations in which the IGBTs are always in the on state, it is necessary to replace the damaged components, as the converter does not allow to operate in any way, i.e., the current will increase until it damages other components or until the action of the protection circuit. This situation also occurs when the problem is related to the diodes. The 5L-PFC rectifier is also very relevant since it does not present any specific requirements regarding dead-time issues, since only one of the IGBTs of each set $\left(g_{1}, g_{2}\right.$ or $\left.g_{3}, g_{4}\right)$ is controlled during a period of the control algorithm. In the positive half-cycle only the IGBTs $g_{l}$ and $g_{4}$ are controlled and, therefore, it is not necessary to guarantee dead-time between the IGBTs $g_{2}$ and $g_{3}$. Similarly, in the negative half-cycle, only the IGBTs $g_{2}$ and $g_{3}$ are controlled and, therefore, it is not necessary to guarantee dead-time between the IGBTs $g_{l}$ and $g_{4}$. The ac-side current is defined by the status assumed by the 5L-PFC rectifier during each sampling period of the control algorithm. The most convenient states that the 5L-PFC rectifier can assume are summarized in Fig. 2, for both positive and negative half-cycles of the grid voltage. In the positive half-cycle (Fig. 2(a-c)), the IGBT $g_{l}$ and the antiparallel diode of the IGBT $g_{2}$ are used to produce the zero level $\left(v_{x y}=0\right)$. The level $+v_{d c} / 2\left(v_{x y}=v_{d c} / 2\right)$ is obtained with the diode $d_{l}$, the IGBT $g_{4}$, and the antiparallel diode of the IGBT $g_{3}$. The level $v_{d c}\left(v_{x y}=v_{d c}\right)$ is obtained with the diodes $d_{l}$ and $d_{4}$. During the negative half-cycle (Fig. 2(d-f)), the IGBT $g_{2}$ and the antiparallel diode of the IGBT $g_{l}$ are used to produce the zero level $\left(v_{x y}=0\right)$. The level $-v_{d c} / 2\left(v_{x y}=-v_{d c} / 2\right)$ is obtained with the diode $d_{2}$, the IGBT $\mathrm{g}_{3}$, and the antiparallel diode of the IGBT $g_{4}$. Finally, the level $-v_{d c}\left(v_{x y}=-v_{d c}\right)$ is obtained with the diodes $\mathrm{d}_{2}$ and $\mathrm{d}_{3}$.

\section{Five-Level PFC Rectifier: Control Algorithm}

The ac-side current of the $5 \mathrm{~L}-\mathrm{PFC}$ rectifier was controlled using a model predictive control with finite control set (MPC-FCS) [33][34]. It is important to mention that other possibilities of current control can be selected [35][36]. By a properly selection of the IGBT that is switched, it is possible to force the 5L-PFC rectifier to produce each one of the voltage levels and to the ac-side current to follow its reference.

\section{A. Reference of Current for the ac-Side}

As previously mentioned, the main characteristic of a PFC rectifier is the sinusoidal ac-side current (achieved with a sinusoidal reference), and the controlled dc-side voltage. By measuring the ac-side voltage, it is possible to determine its rms value. Therefore, knowing the required operating power (established by the load on the dc-side), it is possible to define 
the reference of current for the ac-side. Based on these presupposes, the instantaneous value for the ac-side reference of current $\left(i_{a c}{ }^{*}\right)$ is established as:

$$
i_{a c}{ }^{*}(t)=V_{A C}{ }^{-2} v_{a c}(t) p_{a c}(t),
$$

where $V_{A C}$ is the rms value of the instantaneous voltage $v_{a c}$. By applying this equation for obtaining the reference of current, it is possible to conclude that the amplitude and phase of $i_{a c} *$ is dynamically determined by the operating power $\left(p_{a c}\right)$, but influenced by the ac-side voltage $\left(v_{a c}\right)$ waveform. This situation is solved using a phase-locked loop, resulting in a reference of current $\left(i_{a c}{ }^{*}\right)$ only dependent of the fundamental component of the ac-side voltage. In fact, it should be mentioned that the operating power $\left(p_{a c}\right)$ of the $5 \mathrm{~L}-\mathrm{PFC}$ rectifier is the sum of the power necessary for the load operation (e.g., can be a dc-dc converter) and the necessary power $\left(p_{c}\right)$ for regulating the voltage across the dc-link capacitors (which is obtained from a PI controller). In terms of discrete implementation for a period of the control algorithm, the previous equation results in:

$$
i_{a c}{ }^{*}[k]=V_{P L L_{A C}}[k]^{-2}\left(\left(v_{d c}[k] * i_{d c}[k]\right)+p_{c}[k]\right) v_{p l l_{a c}}[k] .
$$

Based on the value of the reference of current established in equation (2) and the finite distinct states of the 5L-PFC rectifier, during each control period is selected a state to obtain an ac-side current as close as possible to its reference.

\section{B. Predictive Model and Cost Function}

By analyzing the ac-side voltages and currents of the $5 \mathrm{~L}-\mathrm{PFC}$ rectifier, the following equation is obtained:

$$
\frac{d i_{a c}(t)}{d t}-L^{-1} v_{a c}(t)+L^{-1} v_{x y}(t)=0 .
$$

In digitally controlled applications, the forward Euler approximation is commonly used for the discretization of continuous-time model. Therefore, applying it in equation (3), results in the discrete-time model described by:

$$
T^{-1}\left(i_{a c}[k+1]-i_{a c}[k]\right)-L^{-1} v_{a c}[k]+L^{-1} v_{x y}[k]=0 .
$$

Since the objective is to control the ac-side current, equation (4) can be shortened by:

$$
i_{a c}[k+1]=i_{a c}[k]+T L^{-1}\left(v_{a c}[k]-v_{x y}[k]\right) .
$$

Knowing the reference of current $\left(i_{a c}{ }^{*}\right)$ for the ac-side (equation 2), as well as the predicted current (equation 5), the following simple cost function is applied:

$$
g[k+1]=\left\|i_{a c}{ }^{*}[k+1]-i_{a c}[k+1]\right\|^{2} .
$$

Since it is necessary to know the value of the reference of current at $[k+1]$, it was extrapolated according to [3]. Based on the obtained result from the cost function, the state of the $5 \mathrm{~L}-\mathrm{PFC}$ is selected.

\section{FIVE-LEVEL PFC RECTIFIER: EXPERIMENTAL VALIDATION}

Fig. 3 shows the laboratory workbench, which shows the power prototype and the digital control stage. Regarding the development of the power converter (as in Table I), IGBTs model FGA25N120FTDTU and diodes model DUR6060W were used. As a storage element on the ac-side, i.e., the coupling filter with the grid, an inductor of $3 \mathrm{mH}$ was used. On the other hand, two sets of capacitors, each with a nominal value of $2 \mathrm{mF}$, were used as the energy storage element on the

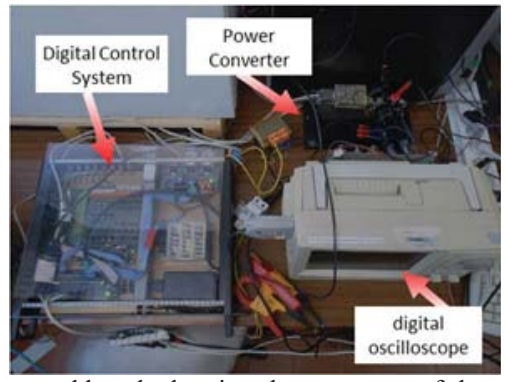

Fig. 3. Laboratory workbench showing the prototype of the proposed 5L-PFC rectifier, with its digital control system stage.

Table. I. Key parameters of the 5L-PFC rectifier.

\begin{tabular}{c|c}
\hline \hline Parameter & Value \\
\hline \hline IGBT & FGA25N120FTDTU \\
Diode & DUR6060W \\
ac-side Inductor & $3 \mathrm{mH}$ \\
dc-side Capacitor & $2 \mathrm{mF}$ \\
\hline \hline
\end{tabular}

dc-side. The digital control stage is mainly focused on the DSP F28335 of the Texas Instruments C2000 family. Since the DSP is not directly connected to the 5L-PFC rectifier, an additional set of circuits were used, namely: (i) A signal conditioning circuit to adapt the ac-side voltage, the ac-side current, and the dc-link voltages to the analog inputs of the DSP; (ii) A gate-driver circuit with four channels allowing the adaptation to the common-emitter configuration (based on bipolar voltages of $+15 \mathrm{~V}$ and $-15 \mathrm{~V}$ and constituted by optocouplers model HCPL3120 and NMV1515SC isolated power supplies); (iii) A coordination circuit that interconnects the DSP with the gate-driver circuits, also allowing enable/disable functions of all gate-driver channels through control signals from the DSP or from the signal conditioning circuit (i.e., whenever a variable exceeds the measured nominal value, a signal is sent to the coordination circuit which, in turn, disables the gate-driver circuits). For the measurement of voltage and current values, hall-effect transducers, models LV-25P and LA-55 were used. These transducers are connected directly to the signal conditioning circuit. As mentioned, a DSP was used for the digital control, being implemented in $\mathrm{C}$ language and executed at a fixed frequency of $40 \mathrm{kHz}$, and all the tasks necessary for the operation of the control algorithm are executed at this frequency (e.g., reading the variables through the ADC, PLL algorithm, dc-link voltage control, current control, and IGBT selection). The proposed 5L-PFC rectifier has been tested connected to the grid (to verify if it complies with the IEEE 519 - 2014 Std.). The grid voltage has a total harmonic distortion (THD) of $3.3 \%$, measured with a Fluke 435. A result of the proposed 5L-PFC rectifier, when all the IGBTs are turned off, is exhibited in Fig. 4. As expected, it operates as a diode bridge rectifier, having the typical current waveform, with a THD of $81.5 \%$. The voltage $v_{x y}$ has a waveform similar to the grid voltage and both dc-link voltages are balanced, but are not controlled. On the other hand, a result in transient state obtained to validate the operation of the 5L-PFC rectifier is exhibited in Fig. 5. As it turns out, in case \#1 all the IGBTs are turned off and, later, in case \#2 the IGBTs are controlled (according to the control strategy presented in the previous section). In this case $\# 2$, it is verified that the ac-side current becomes sinusoidal, the voltage $v_{x y}$ produced by the converter is defined by the five-levels, and the voltages on the dc-link are 


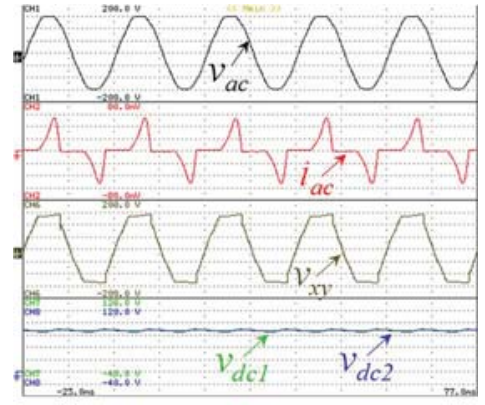

Fig. 4. Experimental results of the proposed 5L-PFC rectifier when all the IGBTs are turned-off: Voltage on the ac-side $\left(v_{a c}: 50 \mathrm{~V} / \mathrm{div}\right)$; Current on the ac-side $\left(i_{a c}: 1 \mathrm{~A} / \mathrm{div}\right)$; Voltage of the converter $\left(v_{x y}: 50 \mathrm{~V} / \mathrm{div}\right)$; Voltage on the dc-side $\left(v_{d c l}: 20 \mathrm{~V} / \mathrm{div}, v_{d c}: 20 \mathrm{~V} / \mathrm{div}\right)$.

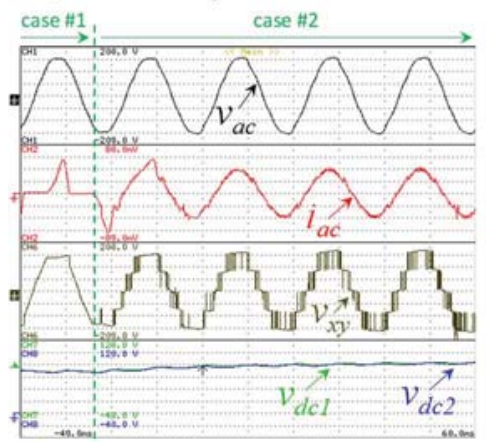

Fig. 5. Experimental results of the proposed 5L-PFC rectifier in transient-state (when the IGBTs are turned-on): Voltage on the ac-side $\left(v_{a c}: 50 \mathrm{~V} / \mathrm{div}\right)$; Current on the ac-side $\left(i_{a c}: 1 \mathrm{~A} / \mathrm{div}\right)$; Voltage of the converter $\left(v_{x y}: 50 \mathrm{~V} / \mathrm{div}\right)$; Voltage on the dc-side ( $\left.v_{d c l}: 20 \mathrm{~V} / \mathrm{div}, v_{d c 2}: 20 \mathrm{~V} / \mathrm{div}\right)$

controlled for their reference and are balanced. After the beginning of case $\# 2$, as soon as the $5 \mathrm{~L}-\mathrm{PFC}$ rectifier reaches the steady state, the measured THD value of the ac-side current was $4.7 \%$. A result showing the division of the currents of the 5L-PFC rectifier is shown in Fig. 6, i.e., the internal currents in the set of IGBTs $g_{1}, g_{2}$ and in the set of IGBTs $g_{3}, g_{4}$. As it turns out, the voltage produced by the converter has the five-levels, and the ac-side current, $i_{a c}$, corresponds to the sum of the currents $i_{a c l}$ and $i_{a c 2}$. The current $i_{a c l}$ is the current measured in the set of IGBTs $g_{1}$ and $g_{2}$, and corresponds to the states where the voltage produced by the converter varies between 0 and $+v_{d c} / 2$, and between 0 and $-v_{d c} / 2$. Summarizing, it is found that this current only exists when it is necessary to produce the level 0 . On the other hand, the current $i_{a c 2}$ is the current measured in the set of IGBTs $g_{3}$ and $g_{4}$, and corresponds to the states in which the voltage produced by the converter varies between $+v_{d c} / 2$ and $+v_{d c}$, and between 0 and $v_{d c} / 2$ and $-v_{d c}$. Summarizing, it is verified that this current only exists when it is necessary to produce the levels $+v_{d c} / 2$ or $-v_{d c} / 2$. A result showing the gate-emitter voltage in each of the IGBTs is presented in Fig. 7. In this figure is also presented the ac-side current, as well as the voltage levels (allowing to identity the IGBTs that are switched in each level). In the positive half-cycle, as it turns out, the IGBTs $g_{1}$ and $g_{4}$ are switched to produce the voltage levels 0 (IGBT $\left.g_{l}\right)$ and $+v_{d c} / 2\left(\right.$ IGBT $\left.g_{4}\right)$. When the voltage produced by the 5L-PFC rectifier varies between $+v_{d c} / 2$ and $+v_{d c}$ only the IGBT $g_{4}$ is switched. In the negative half-cycle, the IGBTs $g_{2}$ and $g_{3}$ are switched to produce the voltage levels 0 (IGBT $g_{2}$ ) and $-v_{d c} / 2$ (IGBT $g_{3}$ ). When the voltage produced by the $5 \mathrm{~L}-\mathrm{PFC}$ rectifier varies between $-v_{d c} / 2$ and $-v_{d c}$, only the IGBT $g_{3}$ is switched. Fig. 8

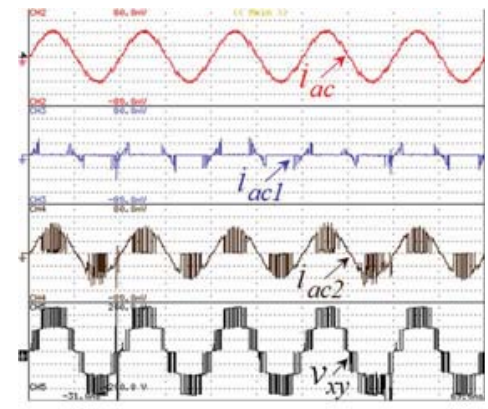

Fig. 6. Experimental results of the proposed 5L-PFC rectifier in steady-state showing the division of the currents: Current on the ac-side $\left(i_{a c}: 1 \mathrm{~A} / \mathrm{div}\right)$; Internal current on the set of IGBTs $g_{1}, g_{2}\left(i_{a c l}: 1 \mathrm{~A} / \mathrm{div}\right)$; Current on the set of IGBTs $g_{3}, g_{4}\left(i_{a c 2}: 1 \mathrm{~A} /\right.$ div $)$; Voltage of the converter $\left(v_{x y}: 50 \mathrm{~V} /\right.$ div $)$.

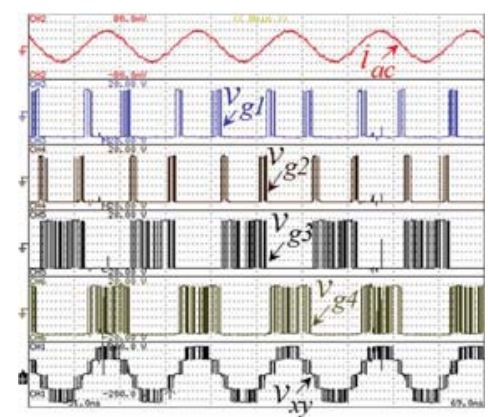

Fig. 7. Experimental results of the proposed 5L-PFC rectifier in steady-state showing a detail of the gate-emitter voltage: Current on the ac-side $\left(i_{a c}\right.$ : $1 \mathrm{~A} /$ div); Gate-emitter voltages in the IGBTs $g_{1}, g_{2}, g_{3}, g_{4}\left(v_{g l}: 5 \mathrm{~V} / \mathrm{div}, v_{g 2}\right.$ : $5 \mathrm{~V} /$ div, $v_{g 3}: 5 \mathrm{~V} /$ div, $\left.v_{g 4}: 5 \mathrm{~V} / \mathrm{div}\right)$; Voltage of the converter $\left(v_{x y}: 50 \mathrm{~V} / \mathrm{div}\right)$.

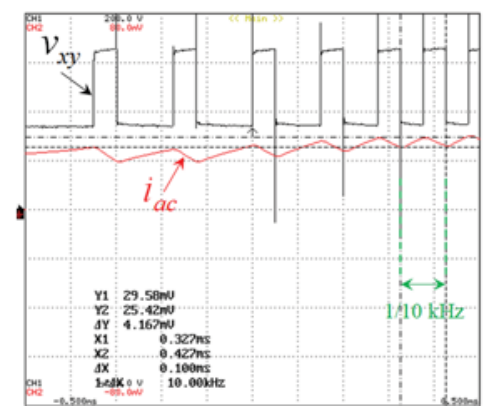

Fig. 8. Experimental results of the proposed 5L-PFC rectifier showing details of the: Current on the ac-side $\left(i_{a c}: 2 \mathrm{~A} / \mathrm{div}\right)$; Voltage of the converter $\left(v_{x y}\right.$ : $50 \mathrm{~V} / \mathrm{div})$.

shows a detailed result allowing to verify the voltage produced by the 5L-PFC rectifier and the ac-side current. In particular, this result was obtained in the positive half-cycle and when the voltage produced by the converter varies between $+v_{d c} / 2$ and $+v_{d c}$. As it turns out, when the voltage is set to $+v_{d c} / 2$ (only the IGBT $g_{4}$ turned-on), the current increases (the inductor stores energy) and when the voltage becomes $+v_{d c}$ (all the IGBTs are turned-off), the current decreases (the inductor provides energy). In this experimental result, the maximum switching frequency was $10 \mathrm{kHz}$ and the current ripple was about $0.42 \mathrm{~A}$.

\section{CONCLUSIONS}

A five-level $(5 \mathrm{~L})$ PFC rectifier is proposed in this paper presenting relevant features when compared with another five-level PFC rectifier. A comprehensive comparison is established along the paper, where it is demonstrated that the proposed 5L-PFC rectifier requires less semiconductors for obtaining the voltage levels, as well as less hardware for the 
gate-driver circuits. Using a developed laboratory prototype (based on discrete components and controlled by a DSP), it was possible to validate the proposed 5L-PFC rectifier in steady and transient state, when connected to the power grid voltage. In the experimental validation it was verified that an ac-side current with low total harmonic distortion, a controlled and balanced dc-side voltage, and a multilevel characteristic were achieved.

\section{ACKNOWLEDGMENT}

This work has been supported by national funds through FCT - Fundação para a Ciência e Tecnologia within the Project Scope: UID/CEC/00319/2019. This work has been supported by FCT Project newERA4GRIDs PTDC/EEI-EEE/30283/2017 and by ERDF - European Regional Development Fund through the Operational Programme for Competitiveness and Internationalisation - COMPETE 2020 Programme, and by National Funds through the Portuguese funding agency, FCT, within project. Mr. Tanta was supported by FCT PhD grant with a reference $\mathrm{PD} / \mathrm{BD} / 127815 / 2016$.

\section{REFERENCES}

[1] Hirofumi Akagi, "Multilevel Converters: Fundamental Circuits and Systems," Proc. IEEE, vol.105, no.11, pp.2048-2065, Apr. 2017

[2] Ma Zhengyou, "Study on the Application of Advanced Power Electronics in Smart Grid," IEEE FGCT International Conference on Future Generation Communication Technologies, pp.96-99, 2017.

[3] Venkata Yaramasu, Marco Rivera, Bin Wu, Jose Rodriguez, "Model Predictive Current Control of Two-Level Four-Leg Inverters-Part I: Concept, Algorithm, and Simulation Analysis," IEEE Trans. Power Electron., vol.28, no.7, pp.3459-3468, July 2013.

[4] Marco Rivera, Venkata Yaramasu, Jose Rodriguez, Bin Wu, "Model Predictive Current Control of Two-Level Four-Leg Inverters-Part II: Experimental Implementation and Validation," IEEE Trans. Power Electron., vol.28, no.7, pp.3469-3478, July 2013

[5] Oscar García, José A. Cobos, Roberto Pietro, Pedro Alou, Javier Uceda, "Single Phase Power Factor Correction: A Survey," IEEE Trans. Power Electron., vol.18, no.3, pp.749-755, May 2003.

[6] João Paulo M. Figueiredo, Fernando L. Tofoli, Bruno Leonardo A. Silva, "A Review of Single-Phase PFC Topologies Based on The Boost Converter," IEEE INDUSCON International Conference on Industry Applications, pp.1-6, Nov. 2010.

[7] Vashist Bist, Bhim Singh, "PFC Cuk Converter-Fed BLDC Motor Drive," IEEE Trans. Power Electron., vol.30, no.2, pp.871-887, Feb. 2015.

[8] Jose I. Leon, Sergio Vazquez, Leopoldo G. Franquelo, "Multilevel Converters: Control and Modulation Techniques for Their Operation and Industrial Applications," IEEE Proc., vol.105, no.11, pp.2066-2081, Nov. 2017.

[9] Krishna Kumar Gupta, Alekh Ranjan, Pallavee Bhatnagar, Lalit Kumar Sahu, Shailendra Jain, "Multilevel Inverter Topologies With Reduced Device Count: A Review," IEEE Trans. Power Electron., vol.31, no.1, pp.135-151, Jan. 2016.

[10] Akira Nabae, Isao Takahashi, Hirofumi Akagi, "A New Neutral-PointClamped PWM Inverter," IEEE Trans. Ind. Appli., vol.IA-17, no.5, pp.518523, Sept. 1981.

[11] Leon M. Tolbert, Fang Zheng Peng, Thomas G. Habetler, "Multilevel Converters for Large Electric Drives," IEEE Trans. Ind. Appl., vol.35, no.1, pp.36-44, Jan. 1999.

[12] José Rodríguez, Jih-Sheng Lai, Fang Zheng Peng, "Multilevel Inverters: A Survey of Topologies, Controls, and Applications," IEEE Trans. Ind. Electron., vol.49, no.4, pp.724-738, Aug. 2002.

[13] Jun Mei, Bailu Xiao, Ke Shen, Leon M. Tolbert, Jian Yong Zheng, "Modular Multilevel Inverter with new Modulation Method and its Application to Photovoltaic Grid-Connected Generator," IEEE Trans. Power Electron., vol.28, no.11, pp.5063-5073, Nov. 2013

[14] Vitor Monteiro, Jose A. Afonso, Joao C. Ferreira, Joao L. Afonso, "Vehicle Electrification: New Challenges and Opportunities for Smart Grids," MDPI Energies, vol.12, no.1, pp.1-20, Dec. 2018.

[15] Rafael Leite, Joao L. Afonso, Vitor Monteiro, "A Novel Multilevel Bidirectional Topology for On-Board EV Battery Chargers in Smart Grids," MDPI Energies, vol.11, no.12, pp.1-21, Dec. 2018.

[16] Hongliang Wang, Lei Kou Yan-Fei Liu, Paresh C. Sen, "A New Six-Switch
Five-Level Active Neutral Point Clamped Inverter for PV Applications," IEEE Trans. Power Electron., vol.32, no.9, pp.6700-6715, Sept. 2017.

[17] Abdel Hamid Loukriz, Sandra Dudley, Terence Quinlan, Stuart D. Walker, "Experimental Realization of a Single-Phase Five Level Inverter for PV Applications," IEEE COMPEL Control and Modeling for Power Electronics, pp.1-6, June 2016

[18] Yifan Yu, Georgios Konstantinou, Branislav Hredzak, Vassilios G. Agelidis, "Operation of Cascaded H-Bridge Multilevel Converters for Large-Scale Photovoltaic Power Plants Under Bridge Failures," IEEE Trans. Ind. Electron., vol.62, no.11, pp.7228-7236, Nov. 2015.

[19] Maha G. Elsheikh, Mahrous E. Ahmed, Emad Abdelkarem, Mohamed Orabi, "Single-Phase Five-Level Inverter with Less Number of Power Elements," IEEE INTELEC International Telecommunications Energy Conference, pp.18, Oct. 2011.

[20] Gabriel H. P. Ooi, Ali I. Maswood, Ziyou Lim, "Five-Level Multiple-Pole PWM AC-AC ConvertersWith Reduced Components Count," IEEE Trans. Ind. Electron., vol.62, no.8, pp.4739-4748, Aug. 2015.

[21] Kui Wang, Lie Xu, Zedong Zheng, Yongdong Li, "Capacitor Voltage Balancing of a Five-Level ANPC Converter Using Phase-Shifted PWM," IEEE Trans. Power Electron., vol.30, no.3, pp.1147-1156, Mar. 2015.

[22] Vitor Monteiro, Andres A. Nogueiras Melendez, Joao C. Ferreira, Carlos Couto, Joao L. Afonso, "Experimental Validation of a Proposed Single-Phase Five-Level Active Rectifier Operating with Model Predictive Current Control," IEEE IECON Industrial Electronics Conference, pp.3939-3944, Nov. 2015.

[23] Hani Vahedi, Philippe-Alexandre Labbé, Kamal Al-Haddad, "Single-Phase Single-Switch Vienna Rectifier as Electric Vehicle PFC Battery Charger," IEEE VPPC Vehicle Power and Propulsion Conference, pp.1-6, Oct. 2015.

[24] Vitor Monteiro, J. G. Pinto, Tiago J. C. Sousa, Andrés A. Nogueiras Meléndez, João L. Afonso, "A Novel Single-Phase Five-Level Active Rectifier for OnBoard EV Battery Chargers," IEEE ISIE International Symposium on Industrial Electronics, vol.4, pp.582-587, June 2017.

[25] F. P. Zeng, G. H. Tan, J. Z. Wang, Y. C. Ji, "Novel Single-Phase Five-Level Voltage-Source Inverter for the Shunt Active Power Filter," IET Power Electronics, vol.3, no.4, pp.480-489, 2010.

[26] Vitor Monteiro, Andres A. Nogueiras Melendez, Joao L. Afonso, "Novel Single-Phase Five-Level VIENNA-Type Rectifier with Model Predictive Current Control,“ IEEE IECON Industrial Electronics Conference, pp.64136418, Nov. 2017.

[27] Hani Vahedi, Kamal Al-Haddad, "A Novel Multilevel Multi-Output Bidirectional Active Buck PFC Rectifier,” IEEE Trans. Ind. Electron., vol.63, no.9, pp.5442-5450, Sept. 2016.

[28] Petar Grbovic, Alessandro Lidozzi, Luca Solero, Fabio Crescimbini, "FiveLevel Unidirectional T-Rectifier for High Speed Gen-Set Applications," IEEE Trans. Ind. Appl., vol.52, no.2, pp.1642-1651, Mar. 2016.

[29] Ataollah Mokhberdoran, Ali Ajami,"Symmetric and Asymmetric Design and Implementation of New Cascaded Multilevel Inverter Topology," IEEE Trans. Power Electron., vol.29, no.12, pp.6712-6724, Dec. 2014.

[30] Hani Vahedi, Philippe-Alexandre Labbé, Hadi Y. Kanaan, Handy Fortin Blanchette, Kamal Al-Haddad, "A New Five-Level Buck-Boost Active Rectifier," IEEE ICIT International Conference on Industrial Technology, pp.2559-2564, Mar. 2015.

[31] P. Roshankumar, P. P. Rajeevan, K. Mathew, K. Gopakumar, Jose I. Leon, Leopoldo G. Franquelo, “A Five-Level Inverter Topology with Single-DC Supply by Cascading a Flying Capacitor Inverter and an H-Bridge," IEEE Trans. Power Electron., vol.27, no.8, pp.3505-3512, Aug. 2012.

[32] Hani Vahedi, Philippe-Alexandre Labbé, Kamal Al-Haddad, "Sensor-Less Five-Level Packed U-Cell (PUC5) Inverter Operating in Stand-Alone and Grid-Connected Modes," IEEE Trans. Ind. Informat., vol.12, no.1, pp.361-370, Feb. 2016.

[33] Vitor Monteiro, Joao C. Ferreira, Andres A. Nogueiras Melendez, Joao L. Afonso, "Model Predictive Control Applied to an Improved Five-Level Bidirectional Converter," IEEE Trans. Ind. Electron., vol.63, no.9, pp.58795890, Sept. 2016.

[34] Vitor Monteiro, Andres A. Nogueiras Melendez, Carlos Couto, Joao L. Afonso, "Model Predictive Current Control of a Proposed Single-Switch Three-Level Active Rectifier Applied to EV Battery Chargers," IEEE IECON Industrial Electronics Conference, Florence Italy, pp.1365-1370, Oct. 2016.

[35] Vitor Monteiro, Joao C. Ferreira, Andres A. Nogueiras Melendez, Carlos Couto, Joao L. Afonso, "Experimental Validation of a Novel Architecture Based on a Dual-Stage Converter for Off-Board Fast Battery Chargers of Electric Vehicles," IEEE Trans. Veh. Tech., vol.67, no.2, pp.1000-1011, Feb. 2018 .

[36] Vitor Monteiro, Joao C. Ferreira, Andres A. Nogueiras Melendez, Carlos Couto, Joao L. Afonso, "Experimental Validation of a Novel Architecture Based on a Dual-Stage Converter for Off-Board Fast Battery Chargers of Electric Vehicles," IEEE Trans. Veh. Tech., vol.67, no.2, pp.1000-1011, Feb. 2018. 